\title{
REPRESENTATION OF SALT SOLUBILITY IN MIXED SOLVENTS: A COMPARISON OF THERMODYNAMIC MODELS
}

Simão P. Pinho and Eugénia A. Macedo

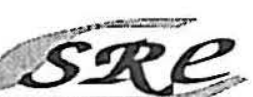

Laboratory of Separation and Reaction Engineering Faculty of Engineering

University of Porto

Portugal 


\section{ABSTRRCT}

A simple and accurate apparatus for the measurement of salt solubilities in mixed solvents by an analytical method is presented. Salt solubility data have been measured for the systems water/methanol $/ \mathrm{NaCl}$, water/methanol/ $\mathrm{KCl}$ at 298.15 and $323.15 \mathrm{~K}$ and for the system water/ethanol/ $\mathrm{NaCl}$ at $298.15,323.15$ and $348.15 \mathrm{~K}$.

To correlate the solubility data two models are proposed:

ane assumes that the salt in solution is in the molecular form and the original UNIQUAC model with linear temperature dependent parameters is used.

a The other takes into consideration the salt dissociation and the original UNIQUAC model is combined with a Pitzer-Debye-Hückel expression to take into account the long-range interaction forces.

In order to simplify the solubility calculations a new formulation is presented involving the symmetric convention for all species. This makes possible the direct access to the solubility product of the salt in terms of its thermodynamic properties. Both models correlate satisfactorily the solubility data although both temperature and electrostatic effects are very important in this type of equilibrium calculations. 